\title{
TAMANHO DE AMOSTRA E NÚMERO DE REPETIÇÕES PARA AVALIAÇÃO DE CARACTERES AGRONÔMICOS EM MILHO-PIPOCA
}

\author{
Sample size and number of replications for assessment of agronomic characters in popcorn
}

\author{
Thiago Rodrigues Catapatti ${ }^{1}$, Manoel Carlos Gonçalves ${ }^{2}$, Maurílio Rezende Silva Neto ${ }^{3}$, Rubens Sobroza ${ }^{4}$
}

\begin{abstract}
RESUMO
Resultados experimentais seguros são obtidos por meio da utilização de adequados tamanhos de amostras e número de repetições. O conhecimento do melhor tamanho de amostra tem relevada importância, quando se deseja reduzir os custos na pesquisa, permanecendo baixos os erros cometidos nas inferências. A utilização de um número adequado de repetições nos experimentos é de fundamental importância para a redução do erro experimental e conseqüente aumento da precisão experimental. Objetivou-se, nesse trabalho, avaliar o tamanho de amostra ideal para caracteres de pré-colheita em milho-pipoca e verificar as implicações do número de repetições na variância residual em caracteres de produtividade e de qualidade. Foram utilizados os genótipos seguintes: variedade BRS ÂNNGELA, híbrido triplo ZÉLIA, variedade UFV-M2 e população avançada do híbrido triplo ZÉLIA. O delineamento experimental foi o de blocos casualizados, em esquema de parcelas subdivididas, com duas, três, quatro, cinco e seis repetições. As parcelas foram constituídas pelos genótipos e as subparcelas pelo tamanho de amostras $(5,10,15,20$ e 25$)$ plantas parcela ${ }^{-1}$. Foi observado que, para avaliar caracteres de pré-colheita podem ser adotadas amostras de 5 a 25 plantas parcela $^{-1}$, sem afetar a precisão experimental. Com o aumento do número de repetições houve aumento na quantidade de caracteres significativos a $1 \%$ de probabilidade, para o efeito de genótipos. Houve maior quantidade de diferenças significativas entre médias de genótipos, para os caracteres de pré-colheita e produtividade, nos números de repetições acima de quatro. Assim podem ser amostradas cinco plantas na parcela, e utilizar quatro repetições.
\end{abstract}

Termos para indexação: Zea mays (L), precisão experimental, amostragem, planejamento experimental.

\begin{abstract}
An adequate experimental design and planning are essential in order to obtain high quality data. Experimental plan ensures correct plot size and shape as well as adequate number of replications and samples. The optimun sample sizes have increasing importance, due to the research cost implication and attempts of keeping to a minimum the research error, remaining low the errors committed in the inferences. The adequate number of replications is of basic importance for minimizing experimental error and increase experimental precision. The objective of our research was to evaluate the ideal sample size for characters of pre- harvest characteristics in popcorn and to study the implications of the number of replications in the residual variance in quality and productivity characteristics. The following genotypes were used: variety BRS ÂNGELA, triple hybrid ZÉLIA, variety UFV-M2 and advanced population of triple hybrid ZELLIA. The experimental design was the one of completely randomized blocks with two, three, four, five and six replications in a split plot treatment design. The genotypes were laid out in the plots and the sample sizes were laid out in the subplots $(5,10,15,20$ and 25$)$ plant $_{\text {plot }}{ }^{-1}$. It was observed that, to evaluate pre-harvest characters one may be assessed from 5 to 25 plants sample size, without impairing the experimental precision. With the increase of the number of replications there was increase in the amount of significant characters with $1 \%$ of probability, for the effect of genotypes. There was a greater amount of significant differences among means of genotypes, for the characters of pre-harvest and yield, for the numbers of replications greater than four. Thus five plants in the plot may be sampled, and four replications may be adopted.
\end{abstract}

Index terms: Zea mays (L), experimental precision, sampling, experimental planning.

(Recebido em 30 de novembro de 2006 e aprovado em 1 de novembro de 2007)

\section{INTRODUÇÃO}

O cultivo de milho-pipoca vem aumentando em várias regiões do Brasil, principalmente em razão do aumento do consumo de pipoca natural e de produtos industrializados (CORREIA et al., 2001). Em 1998, foram importadas 61 mil toneladas, a produção nacional foi de aproximadamente 20 mil toneladas de grãos (GALVÃO et al., 2000). Em 2004, houve uma comercialização de 341 mil toneladas de grãos (AGRIANUAL, 2006). O milho-pipoca,

\footnotetext{
Engenheiro Agrônomo, Mestrando - Faculdade de Ciências Agrárias/FAC - Universidade Federal da Grande Dourados/UFGD - Rodovia DouradosItahum, Km 12 - Cx. P. 533 - 79804-970 - Dourados, MS - tcatapatti@bol.com.br - Bolsista de Iniciação Científica PIBIC/CNPq

${ }^{2}$ Engenheiro Agrônomo, Doutor, Professor Associado - Faculdade de Ciências Agrárias/FAC - Universidade Federal da Grande Dourados/UFGD Rodovia Dourados-Itahum, Km 12 - Cx. P. 533 - 79804-970 - Dourados, MS - manoel.goncalves@ufgd.edu.br

${ }^{3}$ Engenheiro Agrônomo - Faculdade de Ciências Agrárias/FAC - Universidade Federal da Grande Dourados/UFGD - Rodovia Dourados-Itahum, Km 12 Cx. P. 533 - 79804-970 - Dourados, MS - mauriliorezende@hotmail.com

${ }^{4}$ Engenheiro Agrônomo - Departamento Técnico/DETEC - Coamo Agroindustrial Cooperativa - Rua Fioravante João Ferri, 99 - Jardim Alvorada 87308-445 - Campo Mourão, PR - rsobroza_@hotmail.com
} 
pela sua demanda e valor comercial pode representar boa alternativa para pequenos produtores (ANDRADE et al., 2001).

As plantas de milho-pipoca geralmente caracterizamse por serem mais delicadas em relação ao milho comum. São plantas menores, de colmo mais fino, menor número de folhas, prolíficas, maior susceptibilidade a pragas e doenças. Isso se deve ao fato de que os caracteres agronômicos no milho-pipoca são negativamente correlacionados com os caracteres de qualidade da pipoca (CARPENTIERI-PÍPOLO et al., 2002).

Existem falta de informações experimentais com respeito às práticas culturais para o milho-pipoca, e dessa forma vêm sendo adotadas as mesmas recomendações para o milho-comum (ZINSLY \& MACHADO, 1987). As informações de pesquisa sobre o seu cultivo são escassas e as existentes têm sido voltadas principalmente para aspectos de melhoramento genético (BUENO \& PEREIRA, 1993; OLIVEIRA et al., 2003).

A experimentação agrícola no melhoramento de plantas, assim como em outras áreas correlatas, deve ser bem conduzida, pois a precisão experimental caracteriza a qualidade da inferência nos resultados. Tal precisão pode ser melhorada, quando se consegue amenizar alguns efeitos como temperatura, umidade e solo. Desses, o efeito da heterogeneidade do solo, fator possível de ser manipulado, é o que mais prejudica a precisão de um experimento (GOMEZ \& GOMEZ, 1984). O erro experimental pode ser minimizado, a despeito da heterogeneidade do solo, com a utilização de um delineamento experimental adequado ao tamanho e forma de parcelas, ao número de repetições e de tratamentos utilizados e à condução do experimento e coleta dos dados (FERH, 1987; STORCK \& LOPES, 1997).

Na maioria dos estudos com o milho, os principais caracteres de produtividade e de qualidade de grãos são avaliados por meio de amostragens nas parcelas experimentais. É sabido que quanto maior o tamanho de amostra, maior a precisão amostral e experimental e, conseqüentemente, o coeficiente de variação tende a diminuir. Isso acontece porque um aumento do tamanho da $\operatorname{amostra}(\mathrm{n})$ reduz a variância da média amostral $\left(S_{\bar{X}}^{2}\right)$ desde que a variância amostral $\left(\mathrm{S}^{2}\right)$ permaneça constante, pois $S_{\bar{X}}^{2}=S^{2} / n$ (LI, 1969). Mas o problema da determinação do tamanho amostral adequado tem outros aspectos que devem ser considerados. Quanto maior o tamanho amostral, maiores serão o tempo e os gastos com a amostragem. Por outro lado, amostras pequenas podem resultar em menor precisão, o que é indesejável. Assim é de grande interesse determinar o tamanho da amostra a ser utilizado, pois a precisão experimental caracteriza a qualidade da inferência nos resultados.

A utilização de um número adequado de repetições nos experimentos é de fundamental importância para a redução do erro experimental e conseqüente aumento da precisão experimental. A redução do erro experimental possibilita também a obtenção de estimativas mais precisas para os parâmetros genéticos necessários à avaliação de cultivares (RAMALHO et al., 2000).

Objetivou-se no presente trabalho determinar o tamanho ideal de amostra e o número de repetições na avaliação de caracteres de milho-pipoca.

\section{MATERIAL E MÉTODOS}

O experimento foi desenvolvido na Universidade Federal da Grande Dourados, em Dourados - MS (latitude $22^{\circ} 13^{\prime} 16^{\prime \prime S}$, longitude $54^{\circ} 17^{\prime} 01$ ' 'W e altitude de $430 \mathrm{~m}$ ), em um solo classificado como Latossolo Vermelho distroférrico.

O preparo do solo foi convencional, com semeadura manual na primeira quinzena de dezembro 2005, utilizando os seguintes genótipos: variedade BRS ÂNGELA, híbrido triplo ZÉLIA, variedade UFV-M2 e população avançada (primeira geração de recombinação) do híbrido triplo ZÉLIA. A adubação de base foi $400 \mathrm{~kg} \mathrm{ha}^{-1}$ da formulação 04-1408. O delineamento de tratamentos foi o de parcelas subdivididas, sendo as parcelas formadas pelas cultivares e as subparcelas pelos tamanhos de amostras $(5,10,15,20$ e 25 plantas parcela ${ }^{-1}$ ), nas avaliações pré-colheita (uma semana após a maturação). O delineamento experimental foi de blocos casualizados, com duas, três, quatro, cinco e seis repetições. Cada parcela teve duas linhas de cinco metros de comprimento e espaçamento entre linhas de $0,90 \mathrm{~m}$.

A adubação de cobertura foi realizada vinte e cinco dias após emergência, com $50 \mathrm{~kg} \mathrm{ha}^{-1} \mathrm{de} \mathrm{N}$, usando como fonte Uréia. Para o controle de plantas daninhas foram realizadas capinas e no controle de pragas foram feitos duas aplicações, 0,6 $1 \mathrm{ha}^{-1}$ de Metomil e $150 \mathrm{ml} \mathrm{ha}^{-1} \mathrm{de}$ Novaluron.

$\mathrm{Na}$ época de pré-colheita, foram medidos os seguintes caracteres: altura de planta (AP), média das medições feitas do nível do solo à inserção da folhabandeira, em plantas competitivas tomadas ao acaso em cm; altura da espiga (AE), média das distâncias do nível do solo até a inserção da espiga superior, nas mesmas plantas, em cm; número de espigas (NEP), número de espigas por planta; diâmetro do colmo em mm (DC).

Nas avaliações dos caracteres na época e após a colheita, desprezou-se $0,50 \mathrm{~m}$ de cada extremidade usando 
3, 4,5 e 6 repetições, onde foram feitas as seguintes avaliações nas parcelas: número de plantas acamadas (NPAC), contagem das plantas com ângulo de inclinação superior a $45^{\circ}$ em relação à vertical; plantas quebradas (NPQ), número de plantas com colmo inferior a $45^{\circ} \mathrm{em}$ relação à vertical; porcentagem de plantas com sintomas de enfezamento na parcela (ENFZ); contagem de espigas mal empalhadas na parcela (EME); diâmetro da espiga em $\mathrm{mm}$ (DE), tomou-se ao acaso três espigas por parcela medindo foi o do terço médio da espiga com o auxílio de um paquímetro; tamanho da espiga em $\mathrm{cm}$ (TE), comprimento da espiga foi mensurado após colheita com uma régua comum; produtividade de grãos (PROD), as espigas de toda a parcela foram trilhadas, e os grãos foram pesados logo após a determinação do teor de umidade a $13 \%$, sendo os dados convertidos em $\mathrm{kg} \mathrm{ha}^{-1}$ e capacidade de expansão (CE), razão entre o volume de pipoca expandida e o volume de grãos antes do pipocamento. Para avaliar a CE, foram tomadas 3 amostras de $30 \mathrm{~mL}$ de grãos, de cada parcela, medida em proveta graduada, estourada em pipoqueira comum e o volume de pipoca expandido foi medido em proveta graduada de $1000 \mathrm{~mL}$.

O conjunto de dados obtidos foi analisado segundo o modelo estatístico descrito a seguir:

$$
Y_{i j k}=\mu+B_{j}+C_{i}+\varepsilon_{i j}+A_{k}+C A_{i k}+\delta_{i j k},
$$

em que:

$u$ : média geral; $B_{i}$ : efeito do j-ésimo bloco $(j=1,2, \ldots, b)$; $C_{i}$ : efeito do i-ésimo cultivar $(i=1,2, \ldots, c) ; \varepsilon_{i j}$ : erro aleatório a; $A_{k}$ : efeito do k-ésimo tamanho de amostra $(k=1,2, \ldots, a)$;

$C A_{i k}$ : efeito da interação do i-ésimo cultivar com o k-ésimo tamanho de amostra; $\delta_{i j k}$ : erro aleatório b.Todas as análises foram realizadas utilizando o aplicativo computacional GENES (CRUZ, 2006).

\section{RESULTADOS E DISCUSSÃO}

O fator genótipos apresentou efeitos significativos para os caracteres altura de planta e altura de inserção da espiga, sendo esses efeitos maiores na medida em que se aumenta o número de repetições. Quando se usaram 5 e 6 repetições foi obtido efeito significativo a $1 \%$ de probabilidade pelo teste F, para dois caracteres. Quando se usaram 4 repetições foi obtido efeito significativo a $1 \%$, para altura de planta e 5\%, para altura de inserção da espiga, com 3 repetições o caractere altura de planta apresentou um efeito significativo a $5 \%$ e em 2 repetições não apresentou efeito significativo para esses caracteres. Os caracteres diâmetro do colmo e número de espigas por planta não apresentaram efeito significativo para qualquer número de repetição estudada, o que indica que esses caracteres são pouco influenciados pela variação no número de repetições (Tabela 1). Assim a escolha do número de repetições, para esses caracteres fica a critério do pesquisador, na busca das informações necessárias para comprovar suas hipóteses, baseando-se no valor das diferenças mínimas que se deseja.

$\mathrm{O}$ número de plantas amostradas na parcela não apresentou efeito significativo nos diferentes números de repetições estudadas. Isso significa que, para a avaliação de caracteres de pré-colheita em milho-pipoca, podem ser adotadas amostras, de 5 a 25 plantas na parcela, sem afetar a precisão experimental (Tabela 1). Freitas et al. (2001), avaliando 10, 8, 6, 4 e 2 plantas por parcela, para o caractere altura da planta de algodoeiro, observaram que à medida que se aumentava o número de plantas, passou a ser mais eficiente a avaliação do efeito de tratamento, ou seja, uma maior significância do efeito de cultivares, assim recomendou 6 plantas por parcela, como tamanho de amostra. Fernandes \& Silva (1996), avaliando tamanhos de amostra variando de 3 a 15 espigas de milho por parcela, para comprimento e diâmetro da espiga e número de grãos por espiga, observaram que, nem sempre, os maiores tamanhos de amostra foram os mais eficientes, sendo recomendadas 11 espigas por parcela. Trabalhando com cebola, Stuker \& Boff (1998) estimaram o tamanho de amostra para avaliação da queima acinzentada, em canteiros de mudas de cebola, utilizando média e variância a partir de pré-amostras de 30 plantas. Quando o número de plantas estimado era superior a trinta, voltava-se ao campo e aumentava-se o tamanho de amostra até 150 plantas. Verificou-se que o número de plantas amostradas variou com o caractere avaliado, o uso de pré-amostras estimou adequadamente os parâmetros populacionais e o número de amostras variou com as épocas de coleta.

Houve efeito significativo para a interação Genótipos X Número de plantas amostradas na parcela, para o caractere número de espigas por plantas (NEP), quando se usou 3, 4, 5, e 6 repetições. Isso significa que, o tamanho de amostra para o (NEP), apresentou comportamento diferente entre as cultivares (Figura 1). Os Genótipos, híbrido Zélia, Zélia avançado e a variedade BRS Ângela, apresentaram o mesmo comportamento em relação ao número de amostras na parcela, onde 5 plantas amostradas representou maior NEP e 25 plantas representou menor NEP. A variedade UFV M-2, apresentou um comportamento inverso, onde 20 e 25 plantas amostradas representaram um maior NEP e 5 plantas amostradas representou um menor NEP. 
Tabela 1 - Resumo da análise de variância para os caracteres altura de planta (AP), altura de espiga (AE), diâmetro do colmo (DC) e número de espigas por planta (NEP), em função de diferentes números de repetições. Dourados - MS, 2006.

\begin{tabular}{|c|c|c|c|c|c|}
\hline \multirow[t]{2}{*}{ Fontes de Variação } & \multirow[b]{2}{*}{ G.L. } & \multicolumn{4}{|c|}{ Quadrados Médios } \\
\hline & & $\mathrm{AP}$ & $\mathrm{AE}$ & $\mathrm{DC}$ & NEP \\
\hline \multicolumn{6}{|c|}{6 Repetições } \\
\hline Blocos & 5 & 1480,874083 & 2661,364121 & 23,750403 & 0,349083 \\
\hline Genótipos (G) & 3 & $9064,919194 * *$ & $1654,55241 * *$ & $5,604359 \mathrm{~ns}$ & $0,209417 \mathrm{~ns}$ \\
\hline Resíduo (a) & 15 & 713,256128 & 227,96521 & 11,421239 & 0,258017 \\
\hline Amostras (A) & 4 & $6,537208 \mathrm{~ns}$ & $13,031792 \mathrm{~ns}$ & $0,127828 \mathrm{~ns}$ & $0,003125 \mathrm{~ns}$ \\
\hline Interação G X A & 12 & $39,622875 \mathrm{~ns}$ & $38,890431 \mathrm{~ns}$ & $0,450262 \mathrm{~ns}$ & $0,24069 *$ \\
\hline Resíduo (b) & 80 & 25,003408 & 41,191021 & 0,632163 & 0,11783 \\
\hline C.V. \% (a) & & 18,19 & 20,67 & 18,02 & 29,38 \\
\hline C.V.\% (b) & & 3,41 & 8,79 & 4,24 & 6,28 \\
\hline \multicolumn{6}{|c|}{5 Repetições } \\
\hline Blocos & 4 & 1821,56035 & 2887,83335 & 28,0171 & 0,5015 \\
\hline Genótipos (G) & 3 & $8475,4345^{* *}$ & $1725,4588 * *$ & $6,5178 \mathrm{~ns}$ & $0,127033 \mathrm{~ns}$ \\
\hline Resíduo (a) & 12 & 840,73275 & 241,621883 & 12,376967 & 0,326367 \\
\hline Amostras (A) & 4 & $16,3576 \mathrm{~ns}$ & $24,36335 \mathrm{~ns}$ & $0,5896 \mathrm{~ns}$ & $0,002 \mathrm{~ns}$ \\
\hline Interação G X A & 12 & $27,379667 \mathrm{~ns}$ & $37,861217 \mathrm{~ns}$ & $0,722467 \mathrm{~ns}$ & $0,37533 * *$ \\
\hline Resíduo (b) & 64 & 24,7259 & 42,986062 & 0,385437 & 0,11963 \\
\hline C.V. \% (a) & & 19,81 & 21,79 & 18,64 & 32,74 \\
\hline C.V.\% (b) & & 3,4 & 9,19 & 3,29 & 6,27 \\
\hline \multicolumn{6}{|c|}{4 Repetições } \\
\hline Blocos & 3 & 2399,948125 & 3686,090458 & 35,412333 & 0,658458 \\
\hline Genótipos (G) & 3 & $6532,949458 * *$ & $1353,964458^{*}$ & $9,832333 \mathrm{~ns}$ & $0,268458 \mathrm{~ns}$ \\
\hline Resíduo (a) & 9 & 795,979347 & 296,458681 & 12,246 & 0,306903 \\
\hline Amostras (A) & 4 & $7,34325 \mathrm{~ns}$ & $27,829062 \mathrm{~ns}$ & $0,697625 \mathrm{~ns}$ & $0,004563 \mathrm{~ns}$ \\
\hline Interação G X A & 12 & $23,653417 \mathrm{~ns}$ & $54,348313 \mathrm{~ns}$ & $1,056708 * *$ & $0,45646 * *$ \\
\hline Resíduo (b) & 48 & 24,805708 & 49,185167 & 0,333937 & 0,011042 \\
\hline C.V.\% (a) & & 19,33 & 23,77 & 18,45 & 31,59 \\
\hline C.V. \% (b) & & 3,41 & 9,68 & 3,05 & 5,99 \\
\hline \multicolumn{6}{|c|}{3 Repetições } \\
\hline Blocos & 2 & 3590,032167 & 4627,4015 & 52,777167 & 0,692667 \\
\hline Genótipos (G) & 3 & $3450,947111^{*}$ & $671,185944 \mathrm{~ns}$ & $10,385111 \mathrm{~ns}$ & $0,228667 \mathrm{~ns}$ \\
\hline Resíduo (a) & 6 & 606,918611 & 323,972611 & 16,318944 & 0,146 \\
\hline Amostras (A) & 4 & $1,77775 \mathrm{~ns}$ & $7,250167 \mathrm{~ns}$ & $0,4925 \mathrm{~ns}$ & $0,0065 \mathrm{~ns}$ \\
\hline
\end{tabular}

Continua... 
Tabela 1 - Continuação...

\begin{tabular}{|c|c|c|c|c|c|}
\hline \multirow[t]{2}{*}{ Fontes de Variação } & \multirow[b]{2}{*}{ G.L. } & \multicolumn{4}{|c|}{ Quadrados Médios } \\
\hline & & AP & $\mathrm{AE}$ & $\mathrm{DC}$ & NEP \\
\hline Interação G X A & 12 & $18,151972 \mathrm{~ns}$ & $68,025944 \mathrm{~ns}$ & $0,683722 \mathrm{~ns}$ & $0,043389 * *$ \\
\hline Resíduo (b) & 32 & 23,241792 & 49,7465 & 0,368917 & 0,012667 \\
\hline C.V. \% (a) & & 16,95 & 28,82 & 21,35 & 21,19 \\
\hline C.V. \% (b) & & 3,3 & 10,12 & 3,21 & 6,24 \\
\hline \multicolumn{6}{|c|}{2 Repetições } \\
\hline Blocos & 1 & 8746,80625 & 8746,80625 & 61,75225 & 0,225 \\
\hline Genótipos (G) & 3 & $103,52625 \mathrm{~ns}$ & $103,52625 \mathrm{~ns}$ & $3,834917 \mathrm{~ns}$ & $0,139667 \mathrm{~ns}$ \\
\hline Resíduo (a) & 3 & 48,75425 & 48,75425 & 21,444917 & 0,163667 \\
\hline Amostras (A) & 4 & $15,389625 \mathrm{~ns}$ & $15,389625 \mathrm{~ns}$ & $0,615625 \mathrm{~ns}$ & $0,0035 \mathrm{~ns}$ \\
\hline Interação G X A & 12 & $92,925625 \mathrm{~ns}$ & $92,925625 \mathrm{~ns}$ & $0,544292 \mathrm{~ns}$ & $0,19667 \mathrm{~ns}$ \\
\hline Resíduo (b) & 16 & 75,767875 & 75,767875 & 0,519875 & 0,14625 \\
\hline C.V.\% (a) & & 9,73 & 9,73 & 25,29 & 23,73 \\
\hline C.V. \% (b) & & 12,13 & 12,13 & 4,05 & 7,09 \\
\hline
\end{tabular}

** Significativo a $1 \%$ de probabilidade, pelo teste F; * Significativo a 5\% de probabilidade, pelo teste F. ns Não significativo a 5\% de probabilidade, pelo teste F.
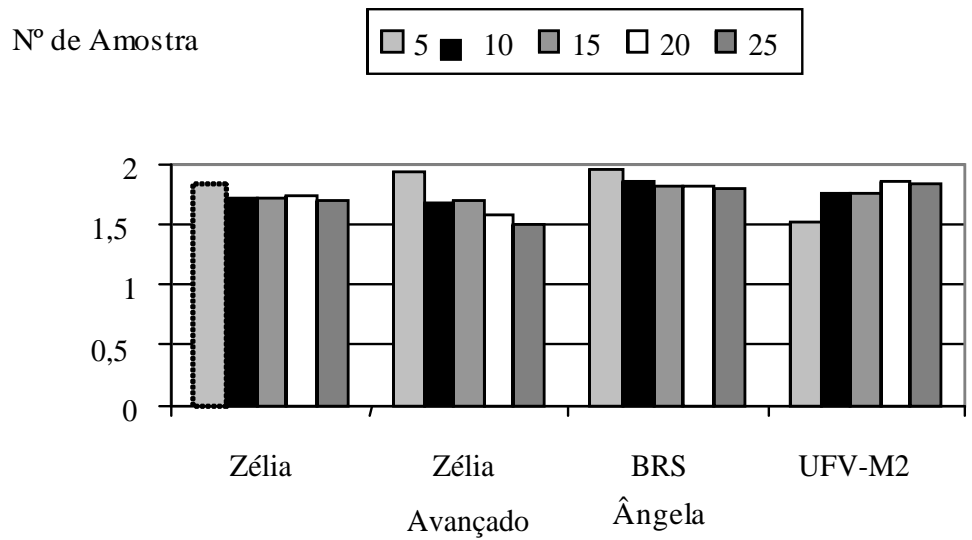

Figura 1 - Representação da interação entre o número de plantas amostrado parcela ${ }^{-1}$ em diferentes genótipos de milhopipoca. UFGD. Dourados-MS, 2006.

Quando se analisa o número de repetições, observase, que não houve uma variação consistente do coeficiente de variação (CV\%) em função do número de repetições para a maioria dos caracteres estudados, isso ocorreu provavelmente pelo pequeno número de genótipos avaliado. Exceção para o caractere produtividade de grãos, onde o $\mathrm{CV} \%$, aumentou à medida que diminuiu o número de repetições (Tabela 2). Alguns caracteres como diâmetro do colmo, número de espigas por planta, tamanho da espiga, número de plantas acamadas e número de plantas perfilhadas, não apresentaram efeito significativo para cultivares, em todos os números de repetições avaliados; isso, provavelmente, ocorreu pelo fato desses caracteres serem pouco influenciados pelas condições ambientais, ou seja, são geneticamente determinados. Ainda na (Tabela 2), observa-se que, com maior número de repetições houve 
maior número de caracteres, com efeito, estatisticamente significativos. A influência do número de repetições no CV\% pode variar de acordo com os caracteres. Os pesquisadores Martin et al. (2005), por meio da metodologia descrita por Hatheway (1961), com o objetivo de verificar se as cultivares de soja (BRS 137 e Fepagro-RS 10), alteram a estimativa do número de repetições, concluíram que, para essas cultivares o número de repetições, que confere uma precisão adequada, é igual a sete. Isso mostra a grande dificuldade em se detectarem diferenças pequenas entre tratamentos com baixo número de repetições.

Analisando a (Tabela 3), observa-se que a variedade BRS Ângela foi a que apresentou um melhor desempenho para todos os caracteres, maior altura de planta e altura de inserção da primeira espiga, maior diâmetro de colmo, melhor empalhamento da espiga, menor porcentagem de plantas com sintomas de enfezamento, maior produtividade e maior capacidade de expansão, seguido da variedade UFV-M2. Isso pode ser explicado pelo fato dessas cultivares terem apresentado uma maior tolerância ao enfezamento. Os cultivares que apresentaram maior suscetibilidade ao enfezamento, como o Zélia e Zélia Avançado, aparentaram altura de plantas e altura de espigas menores, uma menor produtividade de grãos e capacidade de expansão. O que está de acordo com Souza et al. (2003), que verificou redução em altura de plantas, altura de espiga e produtividade de grãos em milho comum. Magalhães et al. (2001), também verificaram a redução em altura de plantas em híbridos comerciais, e sugeriram ser esse um dos fatores a influenciar, negativamente, a disponibilização de fotoassimilados para o enchimento de grãos.

Tabela 2 - Resumo da análise de variância para os caracteres altura de planta (AP), altura da espiga (AE), número de plantas quebradas (NPQ), espigas mal empalhadas com grãos expostas (EME), percentagem de plantas com sintomas de enfezamento (ENFZ), produtividade de grãos (PROD) e capacidade de expansão (CE), em função de diferentes números de repetições. Dourados - MS, 2006.

\begin{tabular}{|c|c|c|c|c|c|c|c|c|c|}
\hline \multirow{2}{*}{$\begin{array}{l}\text { Fontes de } \\
\text { Variação }\end{array}$} & \multirow[b]{2}{*}{ G.L. } & \multicolumn{8}{|c|}{ Quadrados Médios (Q.M.) } \\
\hline & & $\mathrm{AP}$ & $\mathrm{AE}$ & $\mathrm{DE}$ & NPQ & EME & ENFZ & PROD & $\mathrm{CE}$ \\
\hline \multicolumn{10}{|c|}{6 Repetições } \\
\hline Blocos & 5 & 368,467 & 644,539 & 2,303 & 0,590 & 0,646 & 133,465 & 96033,514 & 1,183 \\
\hline Genótipos & 3 & $1605,924 * *$ & $418,084 *$ & $27,582 * *$ & $0,917 *$ & $11,833 * *$ & $1496,747 * *$ & $2219678,076^{* *}$ & $72,118^{* *}$ \\
\hline Resíduo & 15 & 164,057 & 92,947 & 4,222 & 0,220 & 0,253 & 122,795 & 103909,887 & 4,354 \\
\hline $\mathrm{CV}(\%)$ & & 8,69 & 13,41 & 7,49 & 35,92 & 15,31 & 28,59 & 42,25 & 17,005 \\
\hline \multicolumn{10}{|c|}{5 Repetições } \\
\hline Blocos & 4 & 440,616 & 630,586 & 2,706 & 0,725 & 0,775 & 83,248 & 95463,037 & 1,291 \\
\hline Genótipos & 3 & $1502,573 * *$ & $455,061 *$ & $21,347^{*}$ & $0,761 \mathrm{~ns}$ & $8,375^{* *}$ & $1325,603^{* *}$ & $1884662,204^{* *}$ & $69,554 * *$ \\
\hline Resíduo & 12 & 193,463 & 97,573 & 4,584 & 0,226 & 0,185 & 80,060 & 118990,005 & 2,646 \\
\hline $\mathrm{CV}(\%)$ & & 9,49 & 14,22 & 7,82 & 36,96 & 12,96 & 24,8 & 43,58 & 13,17 \\
\hline \multicolumn{10}{|c|}{4 Repetições } \\
\hline Blocos & 3 & 587,488 & 827,434 & 1,087 & 0,330 & 0,513 & 107,445 & 93221,446 & 1,705 \\
\hline Genótipos & 3 & $1238,7 * *$ & $401,682 \mathrm{~ns}$ & $12,127 \mathrm{~ns}$ & $0,465 \mathrm{~ns}$ & $6,488 * *$ & $959,546^{* *}$ & $1682117,696^{* *}$ & $47,971^{* *}$ \\
\hline Resíduo & 9 & 177,632 & 122,354 & 5,313 & 0,121 & 0,234 & 84,342 & 132898,242 & 2,371 \\
\hline $\mathrm{CV}(\%)$ & & 9,1 & 15,76 & 8,52 & 30,84 & 15,22 & 24,52 & 48,24 & 12,49 \\
\hline \multicolumn{10}{|c|}{3 Repetições } \\
\hline Blocos & 2 & 880,630 & 1216,547 & 0,277 & 0,119 & 0,616 & 94,500 & 58864,003 & 1,890 \\
\hline Genótipos & 3 & $670,907 \mathrm{~ns}$ & $184,634 \mathrm{~ns}$ & $5,134 \mathrm{~ns}$ & $0,289 \mathrm{~ns}$ & $4,523 * *$ & $738,092 *$ & $978839,747 *$ & $40,000 * *$ \\
\hline Resíduo & 6 & 170,390 & 76,715 & 4,827 & 0,120 & 0,312 & 83,063 & 151074,733 & 2,117 \\
\hline $\mathrm{CV}(\%)$ & & 8,93 & 12,67 & 8,19 & 34,44 & 18,02 & 25,47 & 55,71 & 11,65 \\
\hline
\end{tabular}

**Significativo a $1 \%$ de probabilidade, pelo teste $\mathrm{F}$; * Significativo a $5 \%$ de probabilidade, pelo teste $\mathrm{F}$; ns Não significativo a $5 \%$ de probabilidade, pelo teste $\mathrm{F}$. 
Tabela 3 - Médias dos cultivares avaliado, para os caracteres altura de planta (AP), altura de espiga (AE), diâmetro da espiga (DE), espigas mal empalhadas com grãos expostas (EME), porcentagem de plantas com sintomas de enfezamento na parcela (ENFZ), produtividade de grãos (PROD) e capacidade de expansão (CE). Dourados - MS, 2006.

\begin{tabular}{|c|c|c|c|c|c|c|c|}
\hline & $\mathrm{AP}$ & $\mathrm{AE}$ & $\mathrm{DE}$ & EME & ENFZ & PROD & $\mathrm{CE}$ \\
\hline Cultivares & \multicolumn{7}{|c|}{6 Repetições } \\
\hline Zélia & $133,28 \mathrm{~b}$ & $65,08 \mathrm{~b}$ & $25,92 \mathrm{~b}$ & $4,44 \mathrm{a}$ & $59,11 \mathrm{a}$ & $230,42 \mathrm{~b}$ & $7,43 \mathrm{~b}$ \\
\hline Zélia Avançado & $135,05 \mathrm{~b}$ & $66,43 \mathrm{~b}$ & $25,7 \quad b$ & 4,5 a & $42,43 \mathrm{ab}$ & $271,83 \mathrm{~b}$ & $12,1 \quad \mathrm{a}$ \\
\hline BRS Ângela & $167,87 \mathrm{a}$ & 83,4 a & $30,32 \mathrm{a}$ & $1,69 \mathrm{~b}$ & $22,78 \mathrm{c}$ & $1449,82 \mathrm{a}$ & $14,98 \mathrm{a}$ \\
\hline \multirow[t]{2}{*}{ UFV-M2 } & $153,08 \mathrm{ab}$ & $72,57 \mathrm{ab}$ & $27,85 \mathrm{ab}$ & $2,52 \mathrm{~b}$ & $30,68 \mathrm{bc}$ & $1099,5 \mathrm{a}$ & $14,57 \mathrm{a}$ \\
\hline & \multicolumn{7}{|c|}{5 Repetições } \\
\hline Zélia & $130,98 \mathrm{~b}$ & $60,38 \mathrm{~b}$ & $26,08 \mathrm{ab}$ & $4,34 \mathrm{a}$ & $59,92 \mathrm{a}$ & $246,48 \mathrm{~b}$ & $6,9 \mathrm{~b}$ \\
\hline Zélia Avançado & $134,5 \mathrm{~b}$ & $64,24 a b$ & $25,38 \mathrm{~b}$ & $4,45 \mathrm{a}$ & $36,18 b$ & $289,98 \mathrm{~b}$ & $13,02 \mathrm{a}$ \\
\hline BRS Ângela & $168,56 \mathrm{a}$ & $82,14 \mathrm{a}$ & $29,96 \mathrm{a}$ & $1,79 \mathrm{c}$ & $22,08 \mathrm{~b}$ & $1446,22 \mathrm{a}$ & $15,02 \mathrm{a}$ \\
\hline \multirow[t]{2}{*}{ UFV-M2 } & $151,98 \mathrm{ab}$ & $71,06 \mathrm{ab}$ & $28,06 \mathrm{ab}$ & $2,71 \mathrm{~b}$ & $30,16 \mathrm{~b}$ & $1183,38 \mathrm{a}$ & $14,46 \mathrm{a}$ \\
\hline & \multicolumn{7}{|c|}{4 Repetições } \\
\hline Zélia & $135,1 \mathrm{~b}$ & $61,75 \mathrm{a}$ & $25,97 \mathrm{a}$ & $4,21 \mathrm{a}$ & $58,25 \mathrm{a}$ & $238,65 \mathrm{~b}$ & $7,35 \mathrm{~b}$ \\
\hline Zélia Avançado & $131,3 \mathrm{~b}$ & 63,4 a & $25,32 \mathrm{a}$ & $4,25 \mathrm{a}$ & $38,95 \mathrm{ab}$ & $178,3 \mathrm{~b}$ & $12,57 \mathrm{a}$ \\
\hline BRS Ângela & $170,15 \mathrm{a}$ & $83,65 \mathrm{a}$ & $29,15 \mathrm{a}$ & $1,65 \mathrm{~b}$ & $22,05 \mathrm{~b}$ & $1478,6 \mathrm{a}$ & $14,72 \mathrm{a}$ \\
\hline \multirow[t]{2}{*}{ UFV-M2 } & $149,45 \mathrm{ab}$ & $71,85 \mathrm{a}$ & 27,8 a & $2,61 \mathrm{~b}$ & $30,55 \mathrm{~b}$ & $1127,55 \mathrm{a}$ & $14,65 \mathrm{a}$ \\
\hline & \multicolumn{7}{|c|}{3 Repetições } \\
\hline Zélia & $140,86 \mathrm{a}$ & $66,97 \mathrm{a}$ & 26,03 a & $4,03 \mathrm{a}$ & $58,3 \mathrm{a}$ & $231,5 \mathrm{ab}$ & $7,1 \mathrm{~b}$ \\
\hline Zélia Avançado & $131,27 \mathrm{a}$ & $61,37 \mathrm{a}$ & $25,4 \mathrm{a}$ & $4,16 \mathrm{a}$ & $33,43 \mathrm{ab}$ & $185,9 \mathrm{~b}$ & $13,4 \mathrm{a}$ \\
\hline BRS Ângela & 166,63 a & $80,03 \mathrm{a}$ & $27,83 \mathrm{a}$ & $1,53 \mathrm{~b}$ & $22,37 \mathrm{~b}$ & $1290,0 \mathrm{a}$ & $14,57 \mathrm{a}$ \\
\hline UFV-M2 & $147,87 \mathrm{a}$ & $68,23 \mathrm{a}$ & $28,03 \mathrm{a}$ & $2,63 \mathrm{ab}$ & $29,03 \mathrm{~b}$ & $1083,37 \mathrm{ab}$ & $14,9 \mathrm{a}$ \\
\hline
\end{tabular}

Médias seguidas de mesmas letras não se diferem estatisticamente, pelo Teste de Tukey, a 5\% de probabilidade, (p>0,05).

\section{CONCLUSÕES}

Para a avaliação de caracteres de pré-colheita em milho-pipoca, podem ser adotadas amostras de 5 a 25 plantas na parcela ${ }^{-1}$, sem afetar a precisão experimental. $\mathrm{O}$ número de repetições influenciou o número de caracteres com efeitos estatisticamente significativos, sendo esse número maior para seis repetições. O número de diferenças significativas entre médias de genótipos, para os caracteres de pré-colheita e produtividade de grãos, foi maior quando foram utilizadas mais de quatro repetições.

\section{AGRADECIMENTOS}

À UFMS/CNPq pela concessão de bolsa PIBIC, ao primeiro autor.

\section{REFERÊNCIAS BIBLIOGRÁFICAS}

AGRIANUAL. Anuário da agricultura brasileira: milho. São Paulo: Instituto FNP, 2006.

ANDRADE, M. J. B.; MORAIS, A. R.; TEIXEIRA, I. R.; SILVA, M. V. Avaliação de sistemas de consórcio de feijão com milho-pipoca. Ciência Agrotécnica, Lavras, v. 25, n. 2, p. 242-250, 2001.

BUENO, L. D.; PEREIRA, P. A cultura do milho pipoca. Lavras: ESAL, 1993. 7 p. (Circular, 7).

CARPENTIERI-PÍPOLO, V.; TAKAHASHI, H. W.; ENDO, R. M.; PETEK, M. R.; SEIFERT, A. L. Correlações entre caracteres quantitativos em milho-pipoca. Horticultura Brasileira, Brasília, v. 20, n. 4, p. 551-554, 2002. 
CORREIA, P. C.; MACHADO, P. F.; ANDRADE, E. T. Cinética de secagem e qualidade de grãos de milho pipoca. Ciência Agrotécnica, Lavras, v. 23, n. 1, p. 134-142, 2001.

CRUZ, C. D. Programa GENES: estatística experimental e matrizes. Viçosa: UFV, 2006. 285 p.

FERH, W. R. Principles of cultivar development. New York: MacMillian, 1987. v. 1, 736 p.

FERNANDES, E. N.; SILVA, P. S. L. Tamanho de amostra e métodos de amostragem para caracteres da espiga do milho. Ciência e Agrotecnologia, Lavras, v. 20, n. 2, p. 252-256, 1996.

FREITAS, J. A. de; SILVA, E. de B.; FALLIERI, J. Tamanho de amostra na parcela para caracterização da altura de plantas de algodoeiro herbáceo Gossypium hirsutum. Ciência Rural, Santa Maria, v. 31, n. 4, p. 583-587, 2001.

GALVÃO, J. C. C.; SAWAZAKI, E.; MIRANDA, G. V. Comportamento de híbridos de milho-pipoca em Coimbra, Minas Gerais. Revista Ceres, Viçosa, v. 47, n. 270, p. 201 218, 2000.

GOMEZ, K. A.; GOMEZ, A. A. Statistical procedures for agricultural research. 2. ed. New York : J. Wiley, 1984. 680 p.

HATHEWAY, W. H. Convenient plot size. Agronomy Journal, Madison, v. 53, n. 4, p. 279-280, 1961.

LI, J. C. R. Statistical inference. Ann Arbop: E. Brothers, 1969. $658 \mathrm{p}$.

MAGALHÃES, P. C.; OLIVEIRA, E.; GOMIDE, R. L.; VASCONCELOS, C.; SOUZA, I. R. P. Aspectos fisiológicos de plantas de milho infectadas por molicutes sob diferentes níveis de água no solo. Revista Brasileira de Fisiologia Vegetal, Londrina, v. 13, p. 293-301, 2001.

MARTIN, T. N.; DUTRA, L. M. C.; JAUER, A. Tamanho ótimo de parcela e número de repetições em soja (Glycine max (L.) Merril). Ciência Rural, Santa Maria, v. 35, n. 2, p. 271-276, 2005.

OLIVEIRA, R. H. de; OLIVEIRA, F. A. de; SANTOS, A. C.; JACOME, A. G. Rendimento e componentes de produção de milho pipoca em função de resíduos de adubação e densidade populacional. Cultura Agronômica, Ilha Solteira, v. 12, n. 1, p. 89-102, 2003.

RAMALHO, M. A. P.; FERREIRA, D. F.; OLIVEIRA, A. C. de. Experimentação em genética e melhoramento de plantas. Lavras: UFLA, 2000. 362 p.

SOUZA, I. R. P. de; OLIVEIRA, E.; OLIVEIRA, C. M. de; PRATES, H. T.; COIMBRA, R. R.; LOPES, J. C. Relação entre características bioquímicas e agronômicas e o enfezamento pálido em milho. Revista Brasileira de Milho e Sorgo, Sete Lagoas, v. 2, n. 1, p. 9-19, 2003.

STORCK, L.; LOPES, S. J. Experimentação II. Santa Maria: UFSM, 1997. 197 p.

STUKER, H.; BOFF, P. Tamanho da amostra na avaliação da queima-acinzentada em canteiros de cebola. Horticultura Brasileira, Brasília, v. 16, n. 1, p. 10-13, 1998.

ZINSLY, J. R.; MACHADO, J. A. Milho pipoca. In: PATERNIANI, E.; VIÉGAS, G. P. Melhoramento e produção do milho. 2. ed. Campinas: Fundação Cargill, 1987. p. 411-422. 